\title{
The influence of alcohol consumption on worldwide trends in mortality from upper aerodigestive tract cancers in men
}

\author{
Gary J Macfarlane, Tatiana V Macfarlane, Albert B Lowenfels
}

\begin{abstract}
Study objectives - To assess current trends in male mortality from cancers of the oral cavity/pharynx, oesophagus, and larynx (upper aerodigestive tract cancers), and relate these to past national consumption of alcohol and smoking of cigarettes. To assess the impact of current trends in alcohol consumption and tobacco smoking on likely future rates of these cancers.

Design - Mortality data for cancers of the oral cavity/pharynx, oesophagus, and larynx were obtained for the years 1955-89 in 25 countries located in North America, Australasia, Europe, and Japan. Information on past and current alcohol consumption was also obtained for these countries, while current national lung cancer rates were used as a proxy measure of past smoking levels.
\end{abstract}

Setting - The World Health Organization mortality database.

Main results - National death rates from cancers of the oral cavity/pharynx, oesophagus, and larynx (considered together) are currently increasing among men and are most strongly associated with the level of per capita consumption of alcohol 20 years previously. They were less strongly associated with the level of alcohol consumption 10 years ago, and only very weakly associated with the current level of lung cancer mortality (a marker of past smoking habits). Regression analysis showed that the national rate of upper aerodigestive tract cancer could be estimated using information on past alcohol consumption and an interaction term between alcohol consumption and current lung cancer rates. Assuming stability in rates of lung cancer, the sizeable increase in alcohol consumption from 5 to 10 litres per capita each year that occurred in some countries during the 1960 s and 70 s means that increases of around 5 per 100000 in the death rate from these cancers can be expected in these countries in the next decades.

Conclusions - Previous alcohol consumption in a country is a strong predictor of deaths from cancers of the upper aerodigestive tract in men, and current increases in death rates can probably be related to increases in consumption which took place during the 1960 s and $70 \mathrm{~s}$. Combined with a reduction in tobacco smoking, which is already taking place in some countries, reversing the trend of increases in consumption of alcohol has the potential for a sizeable impact on the burden of these cancers.

(f Epidemiol Community Health 1996;50:636-639)

Alcohol has been implicated as a causal factor in cancers of the oral cavity, pharynx, oesophagus, and larynx. ${ }^{1}$ In men, alcohol drinking and tobacco smoking together may be responsible for more than three quarters of these tumours. ${ }^{23}$ Recent data have shown that such tumours are becoming more common worldwide, particularly among men. ${ }^{4-7}$ This change is occurring despite steady or decreasing smoking rates in many countries, and in some countries despite falling rates for lung cancer - a tumour known to be strongly linked to tobacco smoking. ${ }^{8}$ The reason for the increase in upper aerodigestive tract tumours is unclear. In this paper, we review current trends in mortality from upper aerodigestive tract cancers worldwide and the relationship of their occurrence to national alcohol and tobacco habits. In addition, estimates of the future burden of mortality from these cancers have been provided. Attention has been focussed on men, since rates in women have historically been low, are currently stable, and since many fewer tumours in women are considered attributable to tobacco and/or alcohol.

\section{Methods}

National cancer mortality data were obtained from the World Health Organization (WHO) mortality database ${ }^{9}$ and material published from the database. ${ }^{45}$ Data were extracted for 25 countries for cancers of the oral cavity and pharynx (ICD-9 (10) rubrics 140-9), oesophagus (150), and larynx (162). Data were for men, by five-year time period, and were related to the period 1955-59 to $1985-89$. They consisted of crude mortality rates, age standardised rates (standardised to the world population), and age truncated rates for the age-group 35-64 years. The countries were selected on the basis of availability of mortality data and information on trends in per capita consumption of alcohol. ${ }^{11}$ Per capita rates are available only for both sexes combined; the use of these figures to estimate alcohol consumption in men is considered reasonable since men, as a group, generally drink considerably more alcohol than women. Data on crude rates of lung cancer 
Table 1 Rates and number of cases of upper aerodigestive tract cancers in 1955-59 and 1985-89

\begin{tabular}{|c|c|c|c|c|c|c|}
\hline Country & $\begin{array}{l}\text { No cases, } \\
1955-59\end{array}$ & $\begin{array}{l}\text { No cases, } \\
1985-89\end{array}$ & $\%$ change & $\begin{array}{l}\text { Rate per } 100000 \\
1955-59\end{array}$ & $\begin{array}{l}\text { Rate per } 100000 \\
1985-89\end{array}$ & $\begin{array}{l}\% \text { Increase } \\
\text { in rate }\end{array}$ \\
\hline Australia & 2139 & 3237 & 51 & 8.61 & 11.39 & 32 \\
\hline Austria & 2539 & 3125 & 23 & 11.09 & 12.95 & 17 \\
\hline Belgium & 3097 & 4515 & 46 & 9.92 & 12.7 & 28 \\
\hline Canada & 3900 & 8601 & 121 & 9 & 11.32 & 26 \\
\hline Czechoslovakia & 3259 & 7860 & 141 & 9.07 & 17.64 & 95 \\
\hline Denmark & 1004 & 1996 & 99 & 6.89 & 10.4 & 51 \\
\hline Finland & 1283 & 1015 & -21 & 14.49 & 6.58 & -55 \\
\hline France & 37450 & 63806 & 70 & 27.62 & 35.34 & 28 \\
\hline ex FRG & 11811 & 28902 & 145 & 7.52 & 13.68 & 82 \\
\hline Hungary & 2833 & 8858 & 213 & 10.68 & 26.64 & 149 \\
\hline Ireland & 1427 & 1414 & -1 & 13.99 & 13.77 & -2 \\
\hline Italy & 17653 & 34799 & 98 & 13.22 & 17.16 & 30 \\
\hline Japan & 16821 & 40612 & 141 & 9.77 & 9.99 & 2 \\
\hline Netherlands & 2082 & 4121 & 98 & 6.68 & 8.66 & 30 \\
\hline New Zealand & 547 & 849 & 55 & 8.47 & 10.92 & 29 \\
\hline Norway & 745 & 1078 & 45 & 6.45 & 6.51 & 1 \\
\hline Poland & 4245 & 17666 & 316 & 7.6 & 17.95 & 136 \\
\hline Portugal & 2520 & 5208 & 107 & 13.32 & 16.14 & 21 \\
\hline Spain & 7972 & 22088 & 177 & 11.21 & 18.08 & 61 \\
\hline Sweden & 1400 & 2397 & 71 & 5.43 & 6.4 & 18 \\
\hline Switzerland & 3362 & 3393 & 1 & 22.11 & 14.41 & -35 \\
\hline United Kingdom & 18936 & 25940 & 37 & 11.4 & 11.99 & 6 \\
\hline United States & 50136 & 75262 & 50 & 10.48 & 10.31 & -2 \\
\hline
\end{tabular}

mortality in men were also extracted for each of the countries, to represent a proxy measure of the past level of smoking.

We combined national mortality rates for the individual sites of oral cavity and pharynx, oesophagus, and larynx into a single "upper aerodigestive tract" group, because all these sites have a similar aetiology and exhibit similar recent trends in occurrence. ${ }^{4}$ The occurrence of cancers on a national basis has been related to previous per capita consumption of alcohol and levels of tobacco smoking. A proxy for the level of tobacco smoking in year $\mathbf{x}$ has been used, namely the crude rate of lung cancer death in year $x+20$. Regression and correlation analyses have been carried out using the $S A S$ statistical package. ${ }^{12}$

\section{Results}

TRENDS IN MORTALITY FROM UPPER

AERODIGESTIVE TRACT CANCERS

Of the 23 countries with available data (the countries of the United Kingdom are presented together), 19 experienced an increase in male mortality rates from upper aerodigestive tract cancers over the 30 years from 1955-59 to 1985-89, while 21 had an increase in the total number of male cases (table 1). Increases in rates were generally between 20 and $60 \%$, with the highest in eastern Europe - Hungary (149\% increase), Poland (136\%), and Czechoslovakia (95\%). The only countries not experiencing an increase were the United States $(-2 \%)$, Ireland $(-2 \%)$, Switzerland ( $-35 \%$ mainly due to a decrease in oesophageal cancer), and Finland $(-55 \%)$.

The total number of deaths from upper aerodigestive tract cancers in the 23 countries increased from 198148 to 352349 over the period 1955-59 to 1985-89. Numbers of deaths increased even in some of the countries with decreasing rates, due to an ageing of the population. In addition to the countries of eastern Europe, which experienced a large increase in the number of cases, Portugal, Spain, the (former) Federal Republic of Germany, Canada, and Japan all had more than double the number of upper aerodigestive tract cancer deaths in 1985-89 than in 1955-59 (table 1).

\section{ESTIMATION OF UPPER AERODIGESTIVE TRACT} CANCER DEATH RATES

A Spearman rank-correlation analysis showed that several variables were associated with national death rates from upper aerodigestive tract tumours in the period 1983-87: per capita consumption of total alcohol beverages in 1963-67 and consumption in 1973-77 had a rank correlation co-efficient $\left(r_{s}\right)$ of approximately 0.80 . There was a weaker correlation $\left(r_{s}=0.30\right)$ between death rates from upper aerodigestive tract cancers and deaths from lung cancer in 1983-87. On stepwise regression analyses (with the dependent variable as the male death rate from upper aerodigestive tract cancer in 1983-87), the variables entered into the model were the level of alcohol drinking during 1963-67 and an interaction term of alcohol consumption during 1963-67 and the male death rate from lung cancer during 1983-87. These analyses excluded two countries, France and Hungary, which are "outliers": their upper aerodigestive tract cancer rates are considerably higher than elsewhere. The inclusion of both countries resulted in poor estimation of their rates, while the maximum likelihood estimates of the parameters in the model were considerably influenced by them. The simple model involving alcohol consumption 20 years previously and the current rates of lung cancer death as a predictor of upper aerodigestive tract cancer death was satisfactory, estimating most countries rates within 2 or 3 per 100000 of the actual rate (fig 1). The model was not significantly improved by the addition of other terms, such as the current (1983-87) mortality rate from lung cancer and alcohol consumption during 1973-77 or $1983-87$.

If we assume that the relationship here will be approximately valid in the future, we may estimate the effect of known changes in the consumption of alcohol in the past 20 years on the future occurrence of upper aerodigestive 


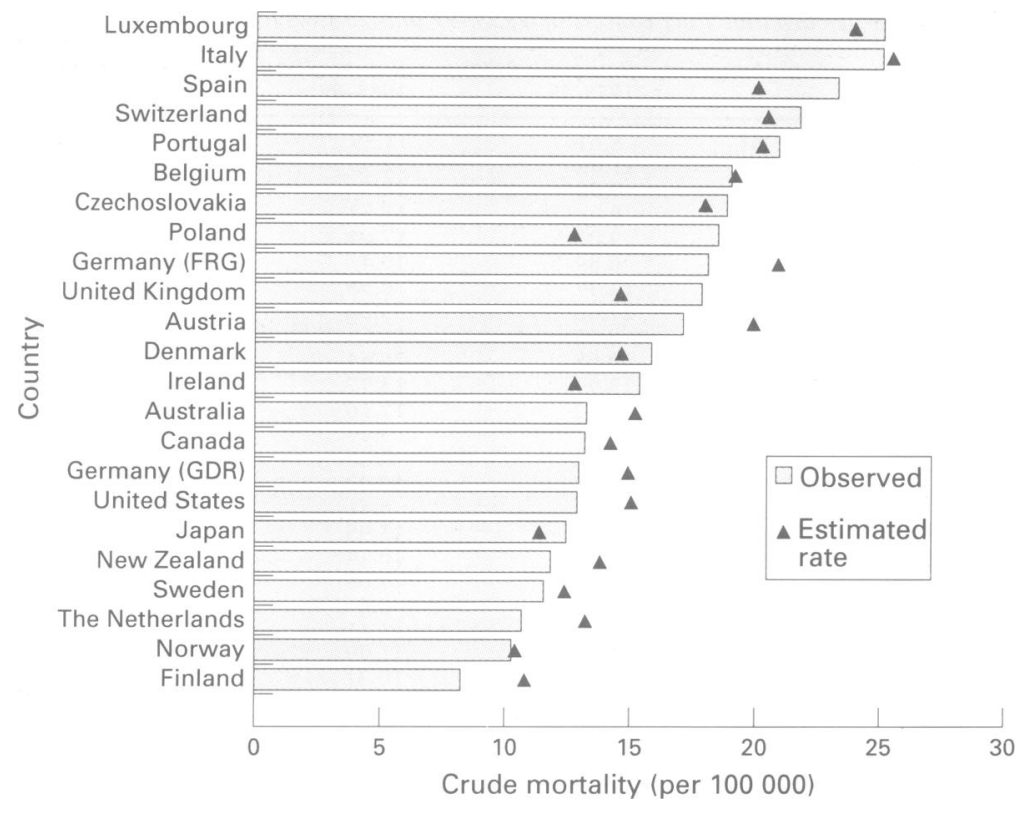

Figure 1 Observed and estimated mortality from upper aerodigestive tract cancers in men, 1983-87.

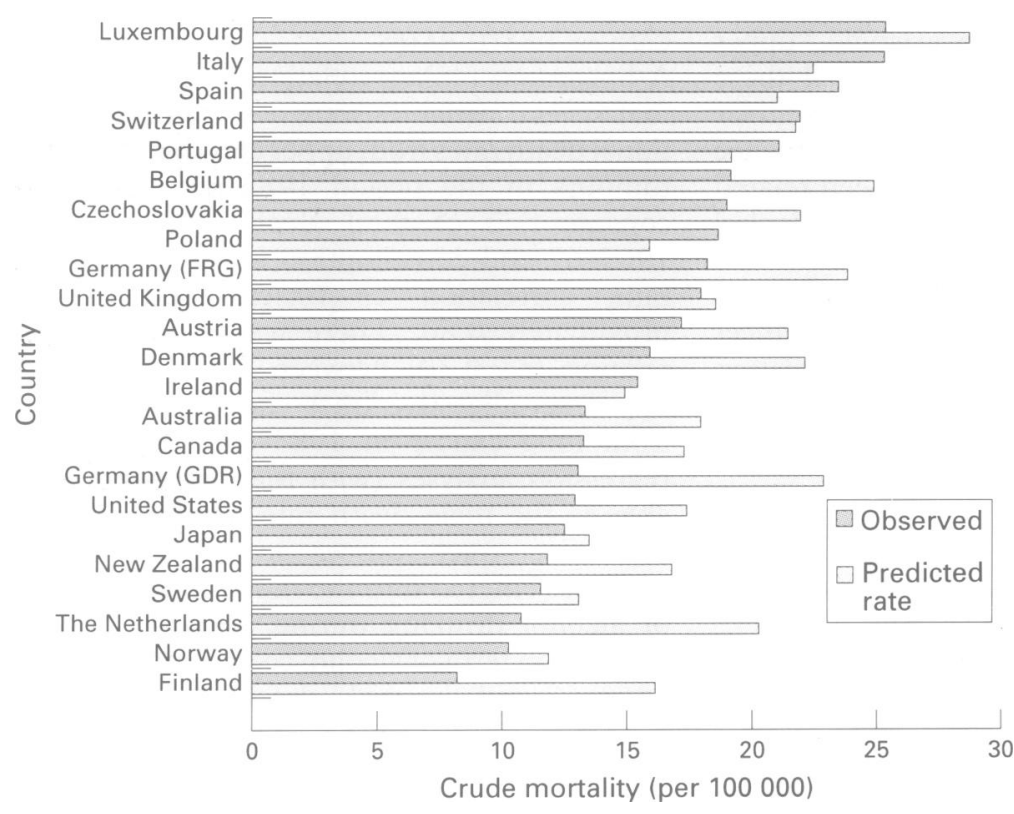

Figure 2 Current (observed rate, 1983-87) and future (predicted rate, 2003-07) mortality from upper aerodigestive tract cancers in men. consumption during the past 20 years will result in a considerable increase in the rate of their occurrence. Particularly large increases are predicted for Germany, with the rates in former eastern Germany increasing from 13 to 23 per 100000 and in former western Germany from 18 to 24 per 100000 . Countries of southern Europe - that is, Spain, Portugal, and Italy with currently high death rates from upper aerodigestive tract cancers, are expected to experience stable or slightly falling rates.

\section{Discussion}

Our findings on worldwide trends in mortality from upper aerodigestive tract cancers confirm previous reports of country specific trends for tumours at individual subsites. ${ }^{813-15}$ These tumours (particularly those occurring in the oral cavity, pharynx, and oesophagus) are becoming appreciably more common in men, and analysis of changing mortality rates in relation to period of birth-time and period of death, show that mortality rates are primarily changing according to period of birth. Each successive cohort of males is experiencing increasing incidence and mortality rates of upper aerodigestive tract tumours at all ages. When such birth cohorts reach older ages, where these diseases have their peak incidence, the absolute increase in the number of cases occurring will be much greater than has been experienced to date. It is of note from the current analysis, that while almost all countries have recorded a sizeable increase in the mortality rates for upper aerodigestive tract cancers, the percentage increase in the number of deaths from these cancers has been much greater. For example, the rates of upper aerodigestive tract cancer deaths in Canada, The Netherlands, and Italy have increased by around a quarter, but the number of deaths has approximately doubled. By contrast, in Switzerland, where upper aerodigestive tract cancer death rates have fallen by $35 \%$, the number of deaths has remained stable. Given the ageing population of most countries, these trends will continue: stable upper aerodigestive tract cancer rates will result in an increased number of deaths, while increasing rates will result in a proportionally much greater number of deaths from the disease.

It is surprising that there was not a reasonably strong association between national mortality rates from lung cancer in men and similar rates for cancers of the upper aerodigestive tract. The primary aetiological factor in both diseases is tobacco smoking, while alcohol drinking, which is a second important factor in the aetiology of upper aerodigestive tract cancers, is also closely related in terms of consumption levels to tobacco smoking. Instead, national death rates from these cancers in men were most strongly associated with national per capita consumption of alcohol 20 years previously. Indeed, using these rates of alcohol consumption together with a term representing the interaction of past alcohol consumption and past tobacco smoking levels (using the proxy of current lung cancer death rates), upper aero- 
digestive tract cancer mortality can be reasonably well estimated. If we assume that a similar relation will hold in the future, we can predict an increase in death rates of between 2 and 5 per 100000 at the beginning of next century.

In these circumstances, prevention becomes extremely important, especially in view of the fact that the aetiology of these tumours is well understood. In countries such as central and eastern Europe, where tobacco smoking and alcohol drinking are becoming more common, efforts aimed at reducing smoking and alcohol consumption should have the highest priority. The success of these measures will have benefits in reducing not only deaths from lung cancer and upper aerodigestive tract cancers but also from many other lethal diseases. Heavy alcohol consumption is also related to death from coronary heart disease, stroke, cardiac arrhythmias, cardiomyopathy, liver cirrhosis, traffic accidents, suicide, and criminal violence. ${ }^{16}$ Moderate levels of alcohol consumption (1-2 drinks per day) are thought to be protective for coronary heart disease and possibly ischaemic stroke, ${ }^{1718}$ and the overall health benefits may be positive at this level of consumption.

It is clearly not easy to effect a reduction in alcohol consumption patterns, especially when these may be established at an early age. However in western Europe, tobacco smoking is now becoming less common in most populations and if this could be combined with moderation in alcohol consumption, upper aerodigestive tract cancers could once again become an uncommon cause of death.

This work was conducted within the framework of a grant awarded to GJ Macfarlane by the Italian Association for $\mathrm{Re}$ search on Cancer for "Studies on the aetiology and prevention of oral and pharyngeal cancer". The work was partly undertaken while GJ Macfarlane and TV Macfarlane were at the Division of
Epidemiology and Biostatistics, European Institute of Oncology, Milan. Additional support came from the CD Smithers Foundation, Inc, Mill Neck, NY. The authors thank Lesley Jordan, University of Manchester, for preparation of the manuscript The manuscript was presented at the $21 \mathrm{st}$ Annual Alcoho Epidemiology Symposium, Porto, Portugal, 5-9th June 1995.

1 Boyle P, Macfarlane GJ, Zheng T, Maisonneuve P, Evstifeeva $\mathrm{T}$, Scully C. Recent advances in the epidemiology of head and neck cancer. Curr Opin Oncol 1992;4:4717.

2 Blot WJ, McLaughlin JK, Winn DM, et al. Smoking and drinking in relation to oral and pharyngeal cancer. Cancer Res 1988;48:3282-87.

3 Negri E, La Vecchia C, Franceschi S, Allessandra T. Aftributable risk for oral cancer in northern Italy. Cancer Epidemiol Biomarkers Prev 1993;2:189-93.

4 La Vecchia C, Lucchini F, Negri E et al. Trends of cancer mortality in Europe. 1955-1989. 1 Digestive sites. Eur $\mathcal{F}$ Cancer 1992;28:132-35.

5 La Vecchia C, Lucchini F, Negri E, et al. Trends of cancer mortality in Europe. 1955-1989. II Respiratory tract, bone, connective and soft tissue sarcomas and skin. Eur f Cancer 1992;28:514-99.

6 Cheng KK, Day NE, Davies TW. Oesophageal cance mortality in Europe - paradoxical time trend in relation to smoking and drinking. $\mathrm{Br} \mathcal{F}$ Cancer 1992;65:613-7.

7 Macfarlane GJ, Boyle P, Evstifeeva TV, Robertson C, Scully C. Trends in oral cancer mortality in males worldwide. The return of an old public health problem. Cancer Causes Control 1994;5:259-265.

8 Macfarlane GJ, Boyle P, Scully C. Oral cancer in Scotland: changing incidence and mortality. BMF 1992;305:1121-3.

9 World Health Organization. World Health Organization mortality database. Geneva: WHO, 1992.

10 World Health Organization. International classification of diseases, injuries and causes of death. 9th rev. Geneva: WHO, 1975.

11 Sparrow M, Brazeau R, Collins H, Morrison RA. Alcoholic beverage taxation and control policies. International survey. Brewers association of Canada. June 1989. 7th ed; $1-471$.

12 SAS Institute Inc. SAS/STAT users' guide. Version 6, vol 2 Cary, NC: SAS, 1989:1-846.

13 Evstifeeva $T$. Trends in cancer mortality in central and eastern European countries: the effect of age, birth-cohort and time-period. Eur $₹$ Cancer 1994;30Asuppl l:S14.

14 Plesko I, Macfarlane GJ, Evstifeeva TV, Obsitnikova A, Kramarova E, Obsitnikova A. Development of registration and cancer incidence rates and trends in Slovakia. Int $\mathcal{f}$ Cancer 1994;56:481-6.

15 Macfarlane GJ, McCredie M, Coates M. Patterns of oral and pharyngeal cancer incidence in New South Wales, Australia. F Oral Pathol Med 1994;23:241-5.

16 Edwards G, Anderson P, Baber TF, et al. The individual's drinking and degree of risk. In: Alcohol policy and the public good. Oxford: Oxford University Press, 1994.

17 Stampfer MJ, Rimm EB, Walsh DC. Alcohol, the heart and public policy. Am $\mathcal{F}$ Public Health 1993;13:801-4.

18 Beaglehole R, Jackson R. Alcohol, cardiovascular diseases and all causes of death: a review of the epidemiological evidence. Drug and Alcohol Review 1992;11:275-90. 